\title{
The Problems and Solutions in Intensive Reading Course Teaching
}

\author{
Yin Liping \\ Foreign Language Department, Arts \& Information Engineering Institute of Dalian Polytechnic \\ University, Dalian, Liaoning, China, 116600
}

hunter2011@foxmail.com

Keywords: Intensive Reading, Problems and limitations, Solutions.

\begin{abstract}
As a comprehensive core course, Intensive Reading plays a decisive role in the final outcome of English teaching for English majors at a College level. This paper analyses the existing problems, limitations, and possible solutions for improving Intensive Reading teaching of this course based on the author's first-hand teaching experience. It also explores ways of reaching for the essence of Intensive Reading teaching.
\end{abstract}

\section{Introduction}

As a compulsory course in Chinese colleges and universities, English Intensive Reading is also regarded as the most important course among the major courses for the English Majors. It is not only carried on throughout the whole English teaching process in the four-year program, it also plays a coherent, supportive, and practical role in other major academic courses for English majors, such as listening, speaking, reading, writing, translation and interpretation. The syllabus of this course clearly states the teaching purpose is to cultivate the students to have a solid reading ability and certain abilities of listening, speaking, writing, and translation and interpretation so that they can apply English to exchange information. It also aims to help students lay a solid language foundation, master a good learning method of the language, and improve their culture attainment so that they can meet the requirements of social and economic development.

As indicated in the name of the course, "Intensive Reading" emphasizes the cultivation of English reading ability, and at the same time, as a comprehensive course, it also concerns the cultivation of the multiple basic skills of the language: listening, speaking, reading, writing, translation, interpretation, and application. The quality of teaching this course would significantly affect the teaching progress of other professional courses. Therefore, the teaching of English Intensive Reading determines the quality of the entire college English major teaching process.

While learning this course, students are required to have a relatively broad knowledge of the history, geography, and culture of the related English-spoken countries, which can be detailed and complicated. Moreover, it also requires higher qualifications for both the teachers and the students since an abundant amount of vocabulary, grammar, language points, and basic skills are involved in the teaching process. However, due to the relatively limited number of teaching hours assigned for this course in the majority of universities and colleges in China and the different levels of the students' basic English proficiency before they approach the course, it's not easy to achieve full intensive excellence of teaching this course and some problems and limitations in the traditional English Intensive Reading classes are inevitably shown.

\section{Problems and Limitations of Intensive Reading Course Teaching}

Teaching Content. In traditional Intensive Reading classes, teaching is based on and around the textbook. Due to the fixed topics and lack of dynamism, it's hard to meet the students' learning needs of all-round development in listening, speaking, reading, writing, translation, interpretation and language application. In fact, to some extent, textbook based teaching restricts the further development of the students' reading abilities and restrains the students' curiosity in learning and students will feel inhibited in expanding their knowledge. As a result, it will prevent the students' overall abilities from developing. Focusing only on the textbooks, teachers tend to make the 
Intensive Reading classes into a traditional middle school English class style, which will bore both themselves and the students. The teachers will find it hard to attract the students' attention and the students will soon lose interest in learning the course.

Teaching Method. For the longest time, traditional Intensive Reading classes were composed of a few major steps including vocabulary instruction, text analysis, translation of the text, grammatical analysis, syntax, and written exercises. The students' various learning habits and learning abilities are hardly the top issue when teachers consider what teaching methods be adopted. In fact, due to the big class size, probably the easiest method for the teachers is to just lecture while the students listen and take notes. It is, in essence, teacher centered, "Duck-stuffing" type of teaching. It requires the students to follow the teacher's instructions unconditionally. Under this "one size fits all" approach, listening to the teachers and taking down what the teachers say become the major tasks for the students in class. In such a learning environment, the students' nonintellectual factors cannot be effectively mobilized and their initiative spirit in participating the classes is not satisfying, not mentioning their practical abilities toward innovation. The outcome of this type of teaching can be far from our expectation.

Teaching Emphasis. Traditional Intensive Reading classes focus on vocabulary and languages points as they appear in the text and the follow up exercises to prepare the students for all kinds of written examinations. However, it lacks sustained, effective and sufficient guidance and training on the understanding and grasp of practical reading skills and English language application abilities while they are supposed to be the core tasks for this course.

Teaching Time. Within the limited class time, teachers often need to rush to complete the established teaching task. After imparting language points and finishing written exercises, there's often not much time left to polish reading skills and refine reading abilities. In the course of time, Intensive Reading classes tend to have the characteristics of a lexicology or grammar class. It gradually loses its reputation and rightful place as the most important English course.

Application of Multimedia. Multimedia technology has been widely used in Intensive Reading classes. However, due to the limited lesson plan time, class teaching time, and limited level of understanding and application of this technology, multimedia technology in the Intensive Reading classes is often used as a way to show language points, and is far from being used to its full potential.

Application of Language. Traditional Intensive Reading classes are teacher-centered. Usually teachers do most of the talking, and students listen and do exercises. Teachers then give them the standard answers and explanations accordingly. Students are placed in a passive position most of the time. They are taught to master the contents of the textbook and there is little chance, if any, to extend and expand beyond the textbook.

Quality of Teachers. As a comprehensive course, the Intensive Reading course requires teachers to be highly qualified. The quality of the teachers is the determinant of the quality of the course. The role of the teacher in an Intensive Reading class is like a director in a well-designed play. A good script, fancy stage, excellent lighting and sound cannot be put to full use without a well-qualified director. Intensive Reading course integrates the basic skills and abilities of listening, speaking, reading, writing, translating, interpreting, and language application. A qualified teacher should not only have excellent language skills, but strong organizational skills in the classroom and a strong classroom management ability.

\section{Solutions of Limitations and Problems Seen in Intensive Reading Course Teaching}

Reset Teaching Content. As a dominant course for the English majors, the Intensive Reading course should, on one hand, strengthen the learning of English reading skills and improve the students' reading abilities, comprehensive skills and the speed of reading; on the other hand, it should also shoulder the responsibility of expanding the students' knowledge, familiarizing the students with western culture through the course learning. Moreover, it's also obliged to cultivate the English language abilities of the students by applying the language. Above all, it should arouse the students' interest of learning and encourage the application of the language. Language 
is a comprehensive skill that cannot be simply disassembled or dispersed. For the teaching of intensive reading, we should always keep in mind that the class should be student-centered. In the course of teaching, teachers should follow the teaching materials as the basic orientation. On the basis of this, relevant background information and cultural knowledge should be introduced, while new and interesting discussion topics being developed should be based on what the students have acquired from their previous learning experiences. Properly set teaching content will inspire and promote the students' involvement in class discussions and help form active and lively student-centered classes. Teachers by then should further enlighten the students to realize, understand and grasp relative language points with the help of the analysis of the vocabulary, texts and exercises in the textbook. Practical application of the language should also be further encouraged.

Expand Extensive Reading outside of class. As Intensive Reading course teachers, we should be aware that languages are practical and accumulative. Teachers should guide the students to make good use of textbooks and grasp the essence of them in class, but at the same time encourage them to not rigidly adhere to the textbooks, and broadly read extracurricular reading materials instead. These reading materials can consist of all kinds of fields and types, and by reading them, the students will soon develop the greater skills of good reading habits, faster reading speed and better understanding. With the good internal and external connection, quantity accumulation will eventually leads to a qualitative leap.

Enrich Teaching Methods. The goal of Intensive Reading teaching concerns not only the acquisition of knowledge and skills, but also includes abilities of thinking and practice; at the same time, it also aims to stimulate and cultivate the students' creativity and non-intelligence factors. According to the modern teaching theory, the teaching of Intensive Reading course is a process of the students' language cognition and development under the guidance of teachers. Students are the main body of this process, and teachers are in guiding positions. Students' subjective initiatives should be fully exerted and passive learning should be avoided. There are no fixed ways of teaching that are applicable for all, and applications of a variety of techniques of teaching should be encouraged to make the classes lively and active. To meet this requirement, teachers are to prepare and carry on lessons based on the practical situation of the students. They should also adopt different teaching methods to tap into the potential of the students, stimulate their interest, fully mobilize their enthusiasm of learning and inspire them to think independently. Student-centered activities like situational teaching and role-play have been proven effective.

Cultivate Applicative Ability. Traditional Intensive Reading classes are teacher-centered, emphasizing the accumulation of language knowledge and paying special attention to the fine analysis of words, phrases, grammatical points and sentence structures. Classes are dominated by basic language teaching and passage comprehension. Teaching tasks are mainly achieved in class. To some extent, this form of teaching will promote students' abilities of obtaining more vocabulary and understanding more grammar and sentence structures, so they can be better prepared for some popular national written tests like College English Tests (CET Band-4 and Band-6), and Tests for English Majors (TEM Band-4 and Band-8). However, according to our experiences, students who go through this examination-oriented ways of teaching usually can achieve high scores but low abilities. They are commonly seen as very weak in listening, speaking and writing. They can easily obtain a Band- 6 certificate without being able to open their mouths and utter a full sentence of English. In all, they lack the ability to put English into practical use. Tracing back, we can find the deep reason of their failure is putting language into practical application. What they have really learned in Intensive Reading classes is to do rote memorization, and later they fail to apply what they have learned to practice. In order to improve the students' language application ability, our classes have to be reformed since learning in classes is the core of Intensive Reading Course. We should put more emphasis on the cultivation of the students' ability of language application instead of focusing on language analysis. The ultimate intention of this course is to improve students' practical reading ability which should be ranked first among all the basic language abilities including listening, reading, writing translating and interpreting. 
Encourage Extracurricular Activities. Language teaching, basically, is a process of practice, and so is the teaching of the Intensive Reading course. The majority of college students in China have only a few hours' learning time in classes each week. In such a limited time, it's almost impossible to achieve the overall improvement on listening, speaking, reading, writing, translating, interpreting and language application. To achieve the all-round goal of teaching Intensive Reading course, it is necessary to create a good language environment and expose the students to an abundance of opportunities to practice what they have learned, so that they can form the sense of English through their participation, exchange of information, experience, perception and practice. As a useful supplement to Intensive Reading course, English extracurricular activities are necessary and inseparable components of the course. Under the directions of the teacher, students can reach their goal by adopting inquiry-based learning through colorful English extracurricular activities. Thus, the single or mutual ways of communication become multi-communicative. Through English extracurricular activities, students are given plenty of opportunities to experience the fun of learning a language and to develop the comprehensive abilities of language application. Meanwhile, students develop an active attitude, active thinking and practice, and a better understanding of a cross-cultural sense and the ability to learn independently. Besides, English extracurricular activities can also arouse the students' interest in learning the language, and becomes a useful impetus to Intensive Reading classroom teaching. Student-centered and people-oriented factors are often shown in the activities. In all, it is an effective supplement to Intensive Reading classes.

Use Multimedia Properly. In the Intensive Reading classes, based on the teachers' understanding of the curriculum and the content of each class, the teacher classifies and integrates the texts, graphics, animations, audio, videos and other multimedia materials to make it easier for the students to comprehend and clearly understand the course, so that students will show more interest in learning. There are some unique advantages of using multimedia courseware: rich expressive power, good interaction and great resource sharing are among the top. Teachers can choose natural, vivid pictures or videos to present the text, which makes it vibrant and intuitive. Supplemented by a different sound or video effect, the use of multimedia courseware makes classes more attractive and lively. Through multimedia, students can watch the teachers' demonstrations and explanation, while they interact with each other. Multimedia has been proven to be helpful for students to improve their abilities in the core areas of language learning (speaking, writing, listening, reading, etc.).

Improve Teachers' Quality. As a designer and director in Intensive Reading course, teachers are expected to be in control of the class. Their qualification is a major determinant of the quality of the course teaching. In the Intensive Reading classes, teachers should improve the ability of internalization, broaden the subject, strengthen the consciousness of scientific research, increase the information content and change the teaching idea of direction development.

The main body of College English Intensive Reading course should be the students. It emphasizes the language interaction and application and is a modern way of teaching involving listening, speaking, reading and writing, etc. In teaching, the exchange of feelings between the teachers and the students is very important. Forming a cordial and harmonious atmosphere is vital. Teachers feel more passionate in teaching while students are more comfortable and relaxed in learning. There is a resultant force formed between the teachers and the students, which sets students in an equal, respectful, trusting and understanding background. They are inspired and encouraged to participate in class discussion and activities more actively and passionately, so they are more likely to discover problems and then solve them. In this way, they have first hand experience in applying the language as a tool.

Students tend to be more relaxed and pleasant in their studies in a harmonious atmosphere. They can be better involved in class activities and feel the improvement of their own. Their attitude toward study becomes better and more active. When they can really feel their improvement and obtain teachers' confirmation and encouragement, their interest in language study is further aroused. They then enter a virtuous circle which eventually leads them to academic success. 


\section{References}

[1] English Section of College Foreign Language Major Teaching Committee. Curriculum of English Teaching in College Level. Foreign Language Teaching \& Research Publishing, Shanghai, Shanghai Foreign Language Education Publishing House, 2000.

[2] D.F. Su, Z.X. Zhuang. A Study on Foreign Language Teaching, Practicing and Methods. Shanghai, Shanghai Foreign Language Education Publishing House, 2008.

[3] H.X. Zhang, L.L. Wang. Advanced English. Beijing, Foreign Language Teaching \& Research Publishing House, 1995.

[4] R. Hu, W.R. Tang, Y. Zhu, An Introduction of Educational Methodology of Educational Technology. Shanghai, Shanghai Foreign Language Education Publishing House, 2005.

[5] R.Q. Liu, On College English Teaching. Foreign Language Teaching \& Research Publishing House, 1999. 